\title{
Epidemiological Aspects of Adherence to the Treatment of Hypertension
}

\author{
Jadelson P. Andrade, Fábio Vilas-Boas, Hildenizia Chagas, Marianna Andrade \\ Salvador, BA - Brazil
}

\begin{abstract}
Objective - To analyze the reasons given by patients for interrupting their pharmacological treatment of hypertension.
\end{abstract}

Methods - We carried out an observational cross-sectional study, in which a questionnaire was applied and blood pressure was measured in 401 patients in different centers of the state of Bahia. The patients selected had been diagnosed with hypertension and were not on antihypertensive treatmentfor at least 60 days. Clinical and epidemiological characteristics of the groups were analyzed.

Results - Of the 401 patients, 58.4\% were females, $55.6 \%$ of whom white; $60.5 \%$ of the males were white. The major reasons alleged for not adhering to treatment were as follows (for males and females respectively): normalization of blood pressure $(41.3 \%$ and $42.3 \%)$; side effects of the medications (31.7\% and 24.8\%); forgetting to use the medication $(25.2 \%$ and $20.1 \%)$; cost of medication $(21.6 \%$ and 20.1\%); fear of mixing alcohol and medication $(23.4 \%$ and $3.8 \%)$; ignoring the need for continuing the treatment (15\% and $21.8 \%)$; use of an alternative treatment $(11.4 \%$ and $17.1 \%$ ); fear of intoxication (9.6\% and $12.4 \%$ ); fear of hypotension (9.6\% and 12\%); and fear of mixing the medication with other drugs (8.4\% and $6.1 \%)$.

Conclusion - Our data suggest that most factors concerning the abandonment of the treatment of hypertension are related to lack of information, and that, despite the advancement in antihypertensive drugs, side effects still account for most abandonments of treatment.

Keywords: systemic arterial hypertension, treatment, adherence

Escola Bahiana de Medicina e Saúde Pública - Salvador

Mailing address: Jadelson Andrade - Av. Juracy Magalhães Jr, 2096 - S/ 411 40920-000 - Salvador, BA, Brazil - E-mail: jad@bahianet.com.br

English version by Stela Maris C. e Gandour
Hypertension is 1 of the major causes of worldwide morbidity and mortality ${ }^{1,2}$, and has been identified as one of the most prevalent risk factors for the development of coronary artery disease, stroke, peripheral vascular disease, renal failure, and congestive heart failure ${ }^{3,4}$. The high prevalence of this clinical condition and the devastating sequelae attributed to an inadequate control of blood pressure have been well documented, the latter including, in addition to cardiovascular and renal diseases, the occurrence of early death. The impact of these data and the perspective of controlling high blood pressure with a well-applied therapeutical strategy justifies the high priority that should be given to its detection by physicians, both general clinicians and specialists ${ }^{5,6}$.

Despite the wide variety and availability of antihypertensive agents for the treatment of hypertension, less than $1 / 3$ of the adult hypertensive patients have their blood pressure adequately controlled. Epidemiological data of the US population have shown that of the $54 \%$ of the individuals knowing their hypertensive condition and receiving treatment for that condition, only $27 \%$ have their blood pressure maintained at recommended levels ${ }^{2,7}$.

One factor that significantly contributes to not controlling blood pressure and motivates studies and research is nonadherence to treatment. Patients who keep their blood pressures well controlled are those presumed to maintain good adherence to treatment. Those whose blood pressures are not under control are those whose adherence to treatment is questionable 8-12 $^{\text {. }}$

Recent studies have shown that of the new patients diagnosed with hypertension and who initiate treatment, approximately $16 \%$ to $50 \%$ discontinue the antihypertensive medication during the first year of use, and that a substantial number of those who continue using the medication do so inadequately ${ }^{13,14}$.

Therefore, nonadherence is a serious problem and should be understood as one of the major obstacles to the success of the treatment of hypertension. Identifying factors determining nonadherence of hypertensive patients to treatment is, therefore, of vital importance in applying the 
therapeutical strategy and in obtaining satisfactory results 15,16 . Once identified, these factors should be permanently incorporated as objects of intervention of the medical practice to obtain the adequate control of blood pressure levels in hypertensive patients, reducing the high epidemiological indices of clinical complications, hospitalizations, and high costs of the final treatment ${ }^{17,18}$.

The objective of this study was to report the reasons alleged by patients to interrupt their treatment of hypertension in a population sample randomly selected in our environment.

\section{Methods}

We sequentially studied patients of both sexes with an established diagnosis of hypertension, who were not on antihypertensive treatment for at least 60 days in each center of 10 cities in the state of Bahia for 6 months. We tried to identify the variables related to the interruption of the antihypertensive treatment instituted.

Standard questionnaires were distributed to $31 \mathrm{car}$ diologists who had private medical offices and ambulatory clinics in the public health care system (SUS) in the selected cities. The questionnaires contained demographic and sociocultural information, data related to the disease, to the beginning of the treatment, reasons for abandoning the treatment, and also all the standardized instructions for data collection, including blood pressure measurement.

Data were gathered from October 1996 to July 1997 and sent for compilation and analysis to the coordinating center of the study. We studied patients of both sexes who had been diagnosed with hypertension according to the criteria of the II Brazilian Consensus on Arterial Hypertension of the Brazilian Society of Cardiology ${ }^{19,20}$.

To be included in the study, the patients had to have undergone antihypertensive medicamentous treatment prescribed by a physician and had abandoned the treatment out of free will at least 60 days before. During the medical visit, data were gathered with a questionnaire applied and blood pressure was measured in a standardized manner, in the right arm with the patient in the sitting position. A previously calibrated mercury sphygmomanometer, scaled from 0 to 300 every $2 \mathrm{~mm} \mathrm{Hg}$, was used, and the mean of 3 measurements taken at intervals of 5-minute rest was considered. Data were typed at the coordinating center, followed by a descriptive analysis, and the chi-square test was used to analyze the differences between the proportions.

\section{Results}

The major demographic characteristics are shown in table I. During the pre-established period of data collection, 401 patients meeting the criteria of the study were identified. Of those, $58.4 \%$ were females, of whom $55.6 \%$ were white; $41.6 \%$ were males, of whom $60.5 \%$ were white.

The major causes for abandoning the treatment are shown in figure 1. Normalization of blood pressure was the major reason found for not adhering to treatment $(41.3 \%$ of males and $42.3 \%$ of the females, $\mathrm{p}=0.84$ ), followed by the side effects of the antihypertensive medication $(31.7 \%$ of the males and $24.8 \%$ of the females $p=0.12$ ), forgetting to use the medication, $(25.2 \%$ of the males and $20.1 \%$ of the females, $\mathrm{p}=0.22)$, and the cost of the medication $(21.6 \%$ of the males and $20.1 \%$ of the females, $\mathrm{p}=0.71$ ).

In regard to race, the major reasons for abandoning the treatment were as follows: normalization of blood pressure ( $43.2 \%$ of the white and $40 \%$ of the black, $\mathrm{p}=0.51$ ); side effects of the medication $(22.9 \%$ of the white and $34.1 \%$ of the black, $\mathrm{p}=0.013)$; forgetting to use the medication ( $22.1 \%$ of the white and $22.4 \%$ of the black, $\mathrm{p}=0.94$ ); and the cost of the medication ( $21.2 \%$ of the white and $26.4 \%$ of the black, $\mathrm{p}=0.21$ ).

Fear of mixing the antihypertensive medication and alcohol was cited as 1 of the major causes for abandoning treatment. This was much more common among males than among females ( $23.4 \%$ of the males and $3.8 \%$ of the females, $\mathrm{p}<0.01$ ), but no difference was observed between the races $(12.5 \%$ of the white and $11.2 \%$ of the black, $\mathrm{p}=0.67)$.

\begin{tabular}{|lrr|}
\hline \multicolumn{2}{|c|}{ Table I - Demographic characteristics of the population studied } \\
\hline Characteristic & $\mathrm{N}$ & $(\%)$ \\
\hline Sex & & \\
Male & 167 & $(41,6)$ \\
Female & 234 & $(58,4)$ \\
Race & & \\
$\quad$ White & 231 & $(57,6)$ \\
Black & 170 & $(42,4)$ \\
Age & & \\
$<40$ years & 42 & $(10,5)$ \\
40 - 60 years & 207 & $(51,6)$ \\
$>60$ years & 152 & $(37,9)$ \\
Educational level & & \\
Illiterate & 26 & $(6,5)$ \\
Primary & 204 & $(50,9)$ \\
Secondary & 136 & $(33,9)$ \\
Superior & 35 & $(8,7)$ \\
\hline
\end{tabular}

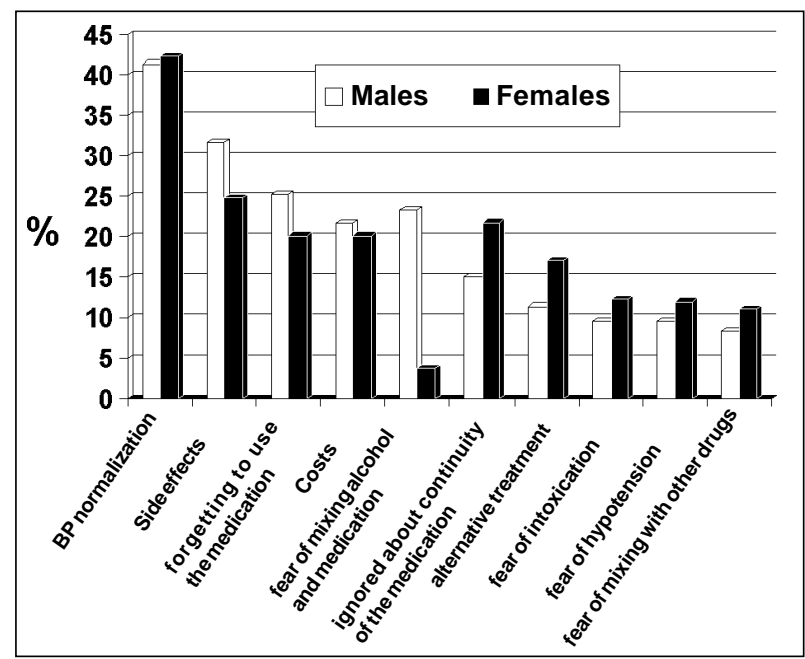

Fig. 1 - Causes of interruption of the treatment. 
In regard to the duration of the interruption of treatment, most patients had interrupted the treatment at least 6 months before the interview $(56.2 \%$ of the males and $61.1 \%$ of the females, $\mathrm{p}=0.33 ; 61 \%$ of the white and $54.7 \%$ of the black, $\mathrm{p}=0.2$ ). With an interruption of treatment between 6 and 12 months, $29.1 \%$ of the males and $25.6 \%$ of the females were found. Only $14.4 \%$ of the males and $14.1 \%$ of the females had interrupted their treatments for more than 12 months (fig. 2).

The longer the duration of hypertension, the greater the percentage of abandonment of the treatment, both for males and females (fig. 3). Those chronic hypertensive patients diagnosed for more than 10 years had the greatest percentage of abandonment $(30.5 \%$ of the males and $32.4 \%$ of the females), followed by those whose diagnosis had been established between 5 and 10 years before ( $24 \%$ of the males and $24.8 \%$ of the females). The hypertensive patients with a more recent diagnosis $(<1$ year $)$ had the lowest index of abandonment ( $12 \%$ of the males and $9 \%$ of the females).

The reasons for resuming the treatment are listed in figure 4 , and the 2 major ones were identification of high blo-

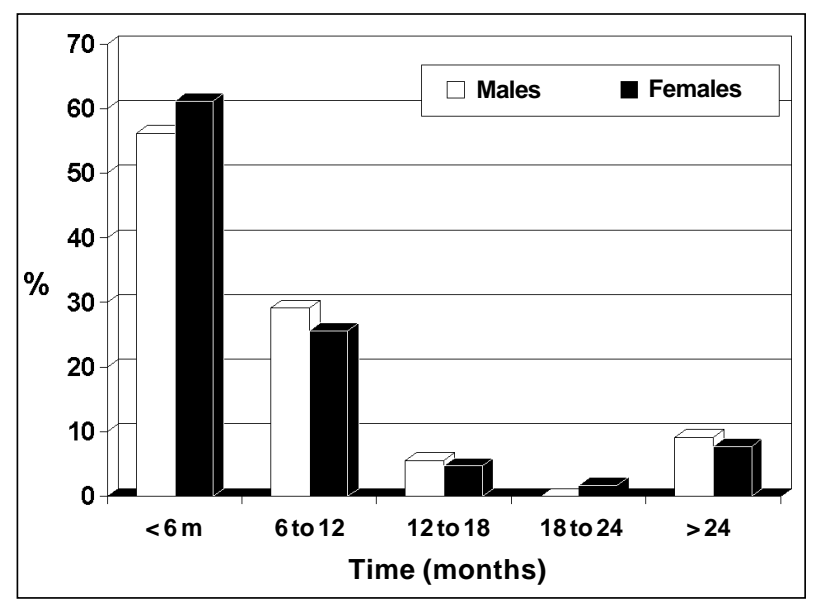

Fig. 2 - Duration of interruption of the treatment according to sex.

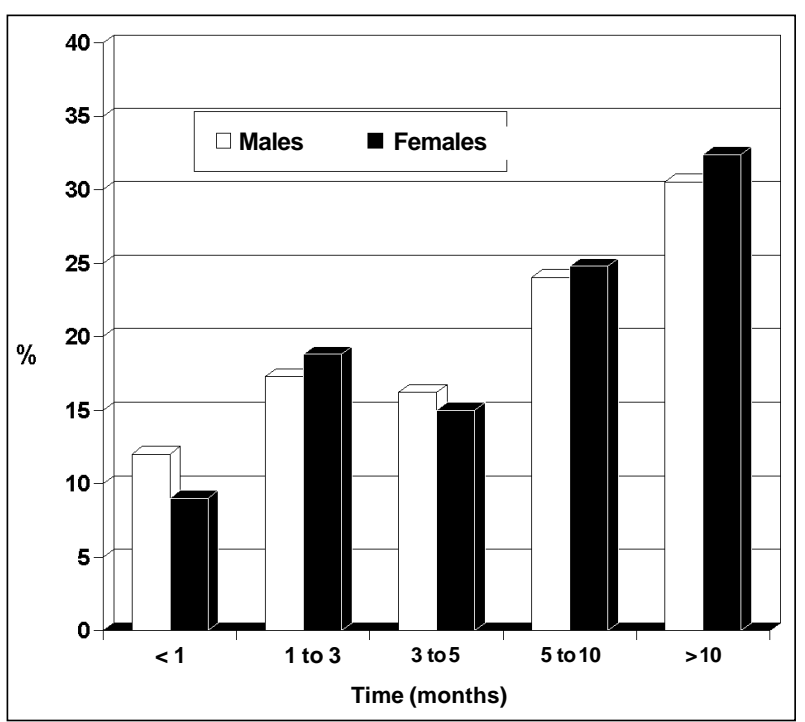

Fig. 3 - Duration of hypertension in the patients who abandoned the treatment. od pressure at the return medical visit $(31.7 \%$ of the males and $34.2 \%$ of the females) and the appearance of symptoms attributed to decompensated hypertension $(30.5 \%$ of the males and $20.2 \%$ of the females). A routine medical visit (checkup) accounted for identification of the problem in a significant part of the population ( $25 \%$ of the males and $14.5 \%$ of the females). The manifestation of a hypertensive crisis also determined the resumption of treatment $(22.2 \%$ of the males and $14.5 \%$ of the females).

On the return medical visit, only $7 \%$ of the white males and $4.5 \%$ of the black males had normal systolic blood pressure. Some patients had systolic blood pressure levels above $210 \mathrm{~mm} \mathrm{Hg}(5.9 \%$ of the white males and $10 \%$ of the black males). Among females, we observed that $10 \%$ of the white and $2.9 \%$ of the black had controlled systolic blood pressure, while $9.2 \%$ and $5.7 \%$, respectively, had systolic blood pressure $=210 \mathrm{~mm} \mathrm{Hg}$.

The analysis of the behavior of diastolic blood pressure showed desired levels in $5 \%$ of the white males and $4.5 \%$ of the black males, and in $9.2 \%$ of the white females and $3.8 \%$ of the black females.

\section{Discussion}

Adherence to long-lasting pharmacological treatment for hypertension has been considered very low, approximately $50 \%$. This nonadherence has been considered 1 of the major factors responsible for the lack of blood pressure control and the already known deleterious implications. The identification of the factors determining nonadherence and a better knowledge about them could allow the implementation of measures that could enable their correction, favoring adherence and providing the adequate control of blood pressure levels ${ }^{15,16}$.

In our study, we tried to identify and describe the reasons determining the interruption of treatment out of free will in patients diagnosed with hypertension. We also analyzed some demographic variables and tried to identify diffe-

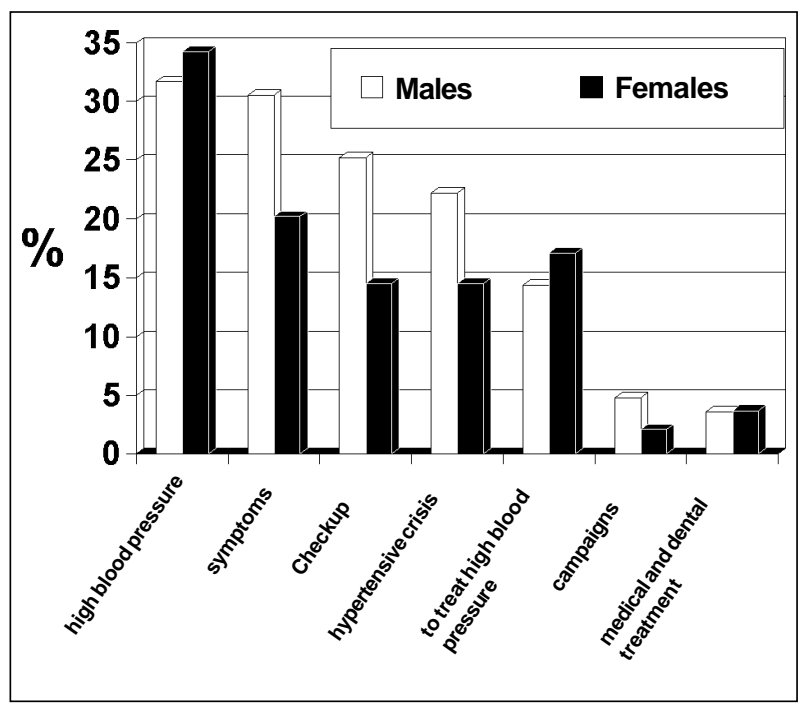

Fig. 4 - Reasons for resuming treatment. 
rentiated causal factors. According to Flack JM et al ${ }^{11}$, females tend to adhere better to antihypertensive treatment and to reach blood pressure control than males do. The major reasons for nonadherence identified in our study are multifactorial and range from lack of adequate guidance to socioeconomic aspects.

Most of the reasons cited by the patients in the present study reflect lack of a more adequate communication between the patient and his physician in regard to the disease and the serious consequences of abandoning treatment. This inadequate communication may be due to both an insufficiency of the information provided and also an incapacity of perception by the patient. Either way, strategies should be clearly developed to improve the communication of the medical information, aiming at increasing adherence to the treatment proposed ${ }^{21,22}$.

The identification of the side effects of the pharmacological treatment used represents the second cause of abandonment of treatment. This is an unexpected situation, because of the availability of modern medications currently on the market with a low profile of adverse side effects. That can be attributed, at least partially, to the difficulty in accessing the new medications, due to economical reasons or even lack of medical experience with them. On the other hand, because the type of antihypertensive medication was not analyzed in the present study, more consistent affirmations about that issue could not be made. There is still the possibility that the side effects reported were not really caused by the drugs used, but can be attributed to symptoms of hypertension. In the TOHMS study (Treatment of Mild Hypertension Study) ${ }^{16}$, the hypertensive patients treated with drugs reported less cephalea than those treated with placebo, even though they had the same mean blood pressure. According to Edmonds et al ${ }^{17}$, the symptoms reported as side effects by hypertensive patients on pharmacological treatment occur mainly at the beginning of therapy and decrease over a period of time, being most probably caused by psychological rather than pharmacological factors.

The ingestion of alcohol is something that should be well considered. Even though hypertensive patients should be advised to reduce alcohol ingestion, the way this information has been provided should be revised, because a poor interpretation, mainly by male patients, may have occurred. The fact that a significant number of males have reported the abandonment of treatment due to the fear of the simultaneous use of the medications and alcohol shows that a significant part of the hypertensive population prefers to continue drinking alcohol to the detriment of the antihypertensive medications. This finding indicates the need for better informing the population about the reasons for reducing the consumption of alcoholic beverages, and also the need for clarifying the absence of medicamentous interaction with alcohol.

Another relevant point was the relation between duration of disease and the degree of abandonment of treatment. In the population studied, the older the diagnosis of hypertension, the greater the degree of treatment abandonment, despite the existence of a longer interval of time to raise patient's consciousness. On the contrary, according to reviews by Haynes ${ }^{18}$ and Lauscher et $\mathrm{al}^{21}$, the lowest rates of adherence were reported in studies carried out immediately after the beginning of therapy, reflecting both loss of follow-up and the initial rate of abandonment.

Educational campaigns to control blood pressure have not been mentioned as a major reason for the return of patients to treatment, as would be expected. Among the reasons cited for the return of patients to treatment, campaigns represent less than 5\%. This, however, neither disqualifies nor blurs the importance of conducting those campaigns. Mudhauser et al ${ }^{22}$ reported the importance and the benefit of an educational program on blood pressure control and adherence to treatment. Many patients in our study may have returned to their physicians or tried to check their blood pressure levels as a consequence of preventive campaigns, which indirectly affects the return to treatment. Maybe we should emphasize in the campaigns the message that the treatment of hypertension a lifetime, and only physicians are authorized to modify it.

\section{References}

1. Semenciw RM, Morrisson HI, Mao Y, et al. Major risk factors for cardiovascular disease mortality in adults: results from the Nutrition Canada Survey Cohort. Int J Epidemiol 1988; 17: 317-24.

2. Burt VL, Whelton P, Rocella EJ, et al. Prevalence of Hypertension in the US adult Population: results from the Third National Health and Nutrition Examination Survey, 1988-1991. Hypertension 1995; 25: 305-13

3. Rabkin SW, Matthewson FAL, Tate RB. Predicting risk of ischemic heart disease and cerebrovascular disease from systolic and diastolic blood pressure. Ann Internal Med 1978; 88: 342-5.

4. MacMahon S, Peto R, Cutler J, et al. Blood pressure, stroke and coronary heart Disease. Lancet 1990; 335: 765-74.

5. Kannel WB. Blood pressure as a cardiovascular risk factor: prevention and Treatment. JAMA. 1996; 275: 1571-6.

6. Ebrahim S. Detection, adherence and control of hypertension for the prevention of Stroke: a systematic review. Health Technol Assessment 1998; 2: 20-8.

7. The six report of the Joint National Committee on Detection, Evaluation, and
Treatment of High Blood Pressure (JNC-VI). Arch Intern Med 1997; 157: 2413-46.

8. Lücher TF, Vetter H, Sieghenthaler W, et al. Compliance in hypertension: facts and concepts. J Hypertens 1985; 3: 3-9.

9. Hershey JC, Morton BG, Davis JB, et al. Patient compliance with antihypertensive medication. Am J Public Health 1980; 70: 1081-9.

10. Feldman R, Bacher M, Campbell C, et al. Adherence to pharmacologic management of hypertension. Can J Public Health 1998; 89: 116-8.

11. Flack JM, Novikov SV, Ferrario CM, et al. Benefits of adherence to anti-hypertensive drug therapy. Eur Heart J 1996; 17(suppl A), 16-20.

12. Teresa MZ, Karin SC. Hypertension and current issues in compliance and patients outcome. Current Hypertension Reports 2000; 2: 510-4.

13. Dusing R, Weisser B, Mengden T, et al. Changes in antihypertensive therapy-the role of adverse efects and adherence. Blood Press 1998; 2: 20-8

14. Caro JJ, Speckman JL, Sals M, et al. Effect of initial drug choice on persistence 
with antihypertensive therapy: the importance of actual practice data. Can J Med Assoc 1999; 160: 41-6.

15. Bartuci MR, Perez S, Pugsley $P$, Lombardo B. Factors associated with adherence in hypertensive patients. ANNA J 1987; 14: 245-8.

16. The treatment of Mild Hypertension Research Group (TOMHS). A randomized, placebo controlled trial of a nutritional-bygienic regimen along with various drug monotherapies. Arch Intern Med Ano????; 151: 1413-23.

17. Edmonds D, Greminger $P$, Venter W, Baumgart $P$, Vetter $H$. The neglected time factor and antihypertensive therapy. A pitfall in evaluating side effects in a cross over study. Postgrad Med J 1988; 83: 40-5.
18. Haynes RB. Improving patient compliance in the management of hypertension. In: Kaplan NM, Ram CV. (Eds). Individualized Therapy of Hypertension. New York: Marcel Dekker Inc., 1995; 257-73.

19. II Consenso Brasileiro de Hipertensão Arterial. J Bras Nefrol 1994; 162: S257-S78.

20. III Consenso Brasileiro de Hipertensão Arterial. HiperAtivo 1999; 6: 106-67.

21. Lauscher TF, Vetter H, Siegenthaler W, Vetter W. Compliance in hypertension: facts and concepts. J Hypertension 1985; 3: 3-9.

22. Mudhauser L, Sawicki PT, Dicilurgeir U, et al. Evaluation of a structured treatment and teaching programme on hypertension in general practice. Clin Exper Hypertension 1993; 15: 124-42. 